\title{
INVESTIGATION OF AEROBIC SOLID FRACTION FERMENTATION PROCESS PARAMETERS FOR ORGANIC MATERIAL
}

Oleg Vechera ${ }^{1}$, Marina Tereshchuk ${ }^{2}$, Viacheslav Chuba ${ }^{1}$, Nataliya Tsyvenkova ${ }^{1,2}$

${ }^{1}$ National University of Life and Environmental Sciences of Ukraine, Ukraine; ${ }^{2}$ Zhytomyr National Agroecological University, Ukraine

olvechera@gmail.com,marfa3127@yandex.ua,vvchuba@ukr.net, nataliyatsyvenkova@gmail.com

\begin{abstract}
The parameters of aerobic solid fraction fermentation of a mixture of solid swine manure, poultry litter with addition of carbon containing plant materials have been investigated. A bioreactor design has been developed. Qualitative rating of the process and end product has been made by measuring such parameters as: process temperature, mixing process, air supply for aeration, $\mathrm{pH}$ and ash. A rational mixing mode for mixture has been found by investigating the dependency of temperature and costs time for fermentation of a mixture. The effective rotational speed of the reactor with periodic stirring and aeration of the compost is $10 \mathrm{rpm}$. This mode allows providing qualitative mixing and saturation of compost with air, to maintain the temperature range of thermophilic mode within $61-63^{\circ} \mathrm{C}$. With this mode of operation, the full fermentation time of the compost is 8 days. Adding wood shavings and straw to the fermented mixture allows increasing the organic value of the resulting compost. The final compost was characterized by good qualitative characteristics, a significant level of humification and no odor emissions. This method of aerobic solid fraction fermentation of organic material represents an effective, low cost approach that could be an interesting opportunity for animal farms.
\end{abstract}

Keywords: aerobic solid fraction fermentation, bioreactor, aeration mode.

\section{Introduction}

With the current intensification of agricultural production, the question of preserving soil fertility in growing crops is rather acute [1]. In order to achieve profitability of cultivation, it is necessary to increase crop yields, which is mostly achieved through the use of a large number of mineral fertilizers and chemical remedies. However, this method of production leads to a decrease in natural fertility and soil degradation $[1 ; 2]$. One way to improve soil fertility is through the use of organic fertilizers in the form of anaerobic digestion substrate and compost based on biological materials [2;3].

In recent decades, biogas reactors have become widespread, allowing the utilization of livestock products of livestock farms and obtaining organic fertilizer in the form of liquid and solid substrates $[4 ; 5]$. Each technology has its disadvantages and advantages.

Significant disadvantages of liquid biogas digestion include the use of large volumes of water to provide the substrate with the moisture content within 80-90\% during the fermentation process, the need for large storage tanks for the substrate due to the short shelf life of the substrate.

The technology of anaerobic digestion of the substrate in the solid form allows the processing of biomass without additional consumption of water, but production facilities are absent [6;7].

One way of producing quality organic fertilizers is by composting biomass. However, the manufacture of quality compost is a lengthy process that involves the need to isolate biomass from the ingress of harmful elements into the environment. According to [8], the main impediment to the widespread adoption of this technology is the low efficiency of this process. According to the research [8], it is possible to intensify the composting process, to increase productivity and to reduce the operating time by preparing composts in burs, with periodic aeration and stirring. However, along with the intensification of the process there is a significant release into the atmosphere of volatile compounds, which worsens the environmental situation.

The composting technology for closed composting can be eliminated. This technology allows increasing the efficiency of the composting process by maintaining optimal thermal modes in the range from 50 to $70{ }^{\circ} \mathrm{C}$, providing aeration with air, and the ability to neutralize intermediate volatile compounds $[9 ; 10]$. However, the composting technology in closed chambers requires considerable energy costs and investment. Also, significant disadvantages include the difficulty of ensuring optimal substrate mixing.

One way to increase the efficiency of the organic compost production process is to use rotary reactors to provide careful mixing of the substrate, the optimum amount of air for aeration, and temperature regimes according to the fermentation phase. However, the analysis of existing scientific 
works [11-13], indicates the need to find optimal modes of operation of drum type installations, depending on the composition of the substrate.

\section{Materials and methods}

The aim of the research was to investigate the effect of substrate mixing intensity with simultaneous purging of the substrate with air on the efficiency of the substrate composting process in a drum-type reactor.

A substrate consisting of $50 \%$ of a mixture of pig manure and straw cuttings (total humidity $45 \%), 20 \%$ of bird droppings and $30 \%$ of plant materials (15\% peat and $15 \%$ hardwood sawdust) was used for the research. The total humidity of the substrate before composting was brought to $60 \%$.

For the experimental research, a drum type reactor was developed (Fig. 1).

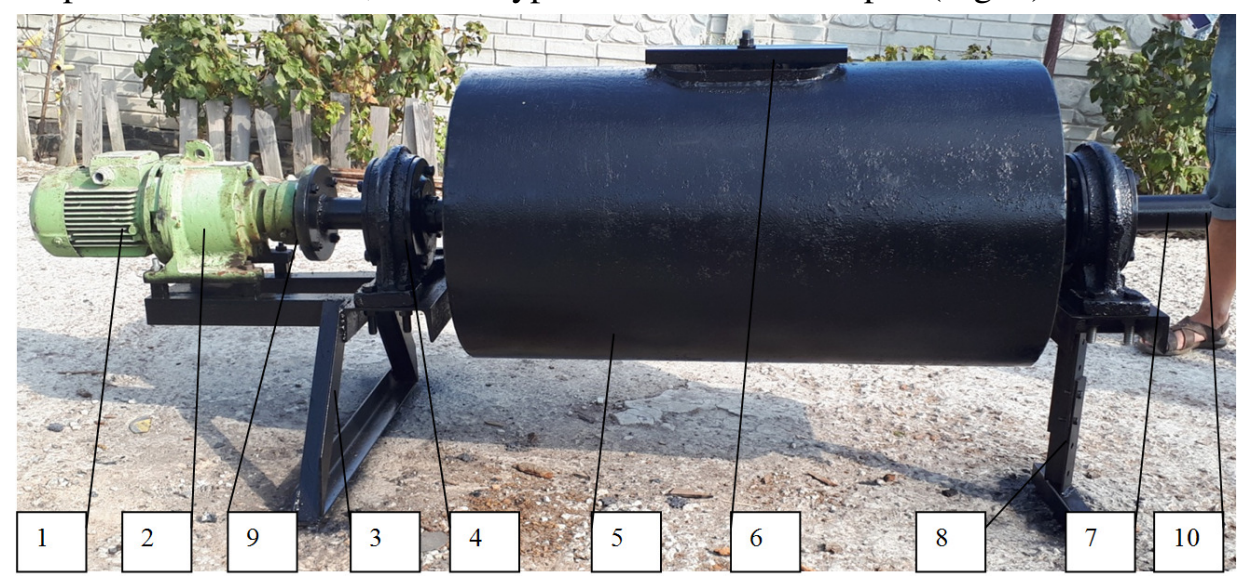

Fig. 1. General view of the pilot plant: 1 - electric motor; 2 - planetary gearbox; 3 - frame; 4 - bearing support; 5 - container; 6 - boot hatch; 7 - axis; 8 - adjustable rack; 9 - connecting muff; 10 - fitting with female thread

The composting plant for bio-organic residues of agricultural origin can be found in Fig.1 and consists of a horizontal sealed container of cylindrical shape 5 with a hatch 6 for loading and unloading the substrate. The loading hatch 6 is equipped with an automatic pressure control valve that opens when the pressure is increased to $2 \mathrm{~atm}$. On the inner surface of the container 5 , for the mixing of the substrate, are fixed concave static blades and four longitudinally placed tubes with nozzles for aeration of the substrate. The container 5 is mounted on the hollow axles 7, which are mounted in the supports 4 on the ball bearings. One axis is made deaf, to which an electromechanical actuator is connected via a flange. The other axis is made in the form of an internal threaded connection, to which the inner tube is connected to the nozzles for aeration of the substrate, and the outer rotary coupling 9 is provided to provide air during the rotation of the reactor 5. The feature of the installation is also a possibility to change the angle of inclination of the axis to the horizon, which, in the first place, affects the angle of installation of static blades. One support is configured to adjust the mounting height of the reactor support (control rack 8). This design allows the angle of inclination of the axis of rotation of the reactor to be varied from 0 to 20 degrees relative to the horizontal surface. The tilt angle adjustment is discrete in 5 degree increments. To measure the temperature of the composted raw material, type $\mathrm{K}$ thermocouples are installed on the inner surface of the container. They provide temperature measurements in different zones, the results of which then can be averaged. As the tank rotates, thermocouples and temperature measurements are scheduled periodically.

The electromechanical actuator consists of a $3.5 \mathrm{~kW}$ electric motor, a planetary gearbox 2 and a frequency converter (HITACHI WJ200) to control the reactor speed. The total unloaded installation weight is $92 \mathrm{~kg}$ and the total reactor volume is 2201.

Loading of raw materials and unloading of finished compost occurs periodically through the loading hatch 6. For a pilot plant, this form of loading is acceptable, allows easy maintenance, cleaning of residual materials, washing, etc.

At the beginning of the experimental studies, the outer surface of the reactor was thermally insulated to reduce heat losses to the environment. The reactor was also housed in a small volume 
room with minimal air movement. During the period when the reactor was not rotating, the check valve was connected to the exhaust ventilation system.

For composting, the drum type 5 container was $50 \%$ filled with a suitable substrate. To ensure the self-heating process of the fermentation of the substrate during composting, periodic stirring was carried out with the simultaneous supply of air for aeration. Substrate stirring was performed for $5 \mathrm{~min}$ every 55 minutes. Also, the substrate temperature was measured at the beginning of mixing. The performance of the air supply system was configured to provide 4 times the amount of air in the reactor compared to the volume of the substrate in the reactor, provided that the safety valve in the reactor loading port is not actuated.

To ensure the movement of the substrate in the longitudinal direction of the drum reactor, the axis of rotation of the drum was periodically changed, setting alternately the angle of inclination of 0 and 10 degrees [14].

During the research, three series of experiments were performed with the reactor rotation rate under stirring, which was $5,10,15$ revolutions per minute, followed by observation of the temperature of the composting regime. To plot the progress of the temperature process, these changes in temperature over the 12 hours were averaged.

Creating a mathematical model was not an aim of the experimental study. To compare and visualize the data obtained during the composting process in different modes of mixing, we used the average of the experimental data sample taken in a certain corresponding time interval. At determinations of the mean arithmetic value for every data sample a standard deviation, dispersion and sampling error were calculated. For the studies performed the maximum sampling error was less than $5 \%$ compared to the arithmetic mean of the experimental parameter.

\section{Results and discussion}

As a result of the executed researches, the dependences of the influences of the frequency of the reactor rotation are obtained on a temperature condition and the motion of the process of punching the substrate (Fig. 2).

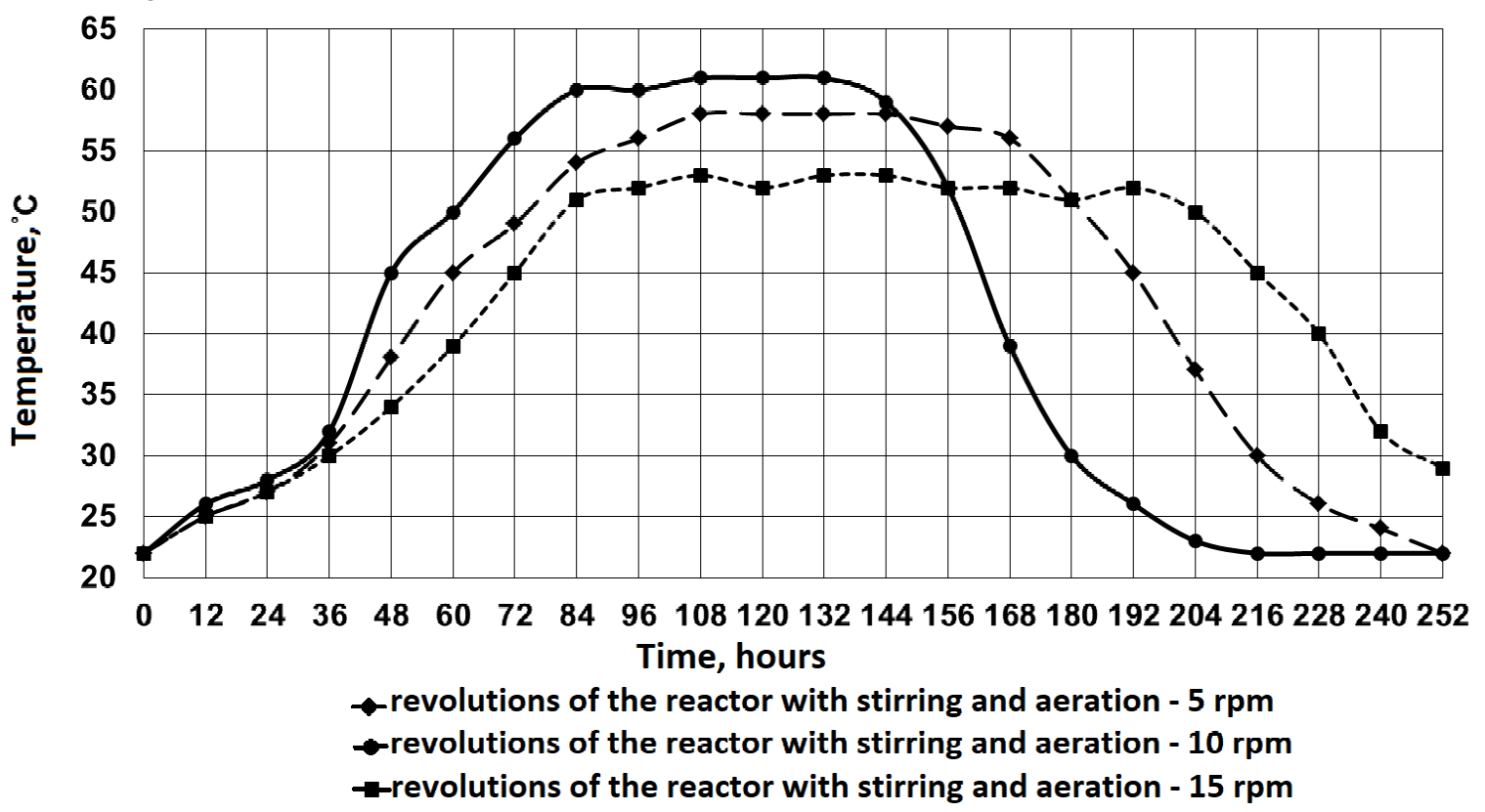

Fig. 2. Temperature regimes of the organic material fermentation process in a drum-type reactor

Analysis of the dependencies obtained, Fig. 1, allows to distinguish four main stages of implementation of substrate fermentation. 
In the first step, slow heating of the mixture to a temperature of $30^{\circ} \mathrm{C}$ was observed in the time interval from 0 to 36 hours. At this stage, no significant influence of the substrate mixing mode on the temperature change was detected.

The second stage is characterized by rapid heating of the mixture and reaching a temperature of $50{ }^{\circ} \mathrm{C}$, which corresponds to the beginning of the thermophilic mode of composting. The experimental data show that at this stage the intensity of heating of the substrate begins to be affected by the mixing mode. So, at a reactor speed of $10 \mathrm{rpm}$ (revolutions per minute) the temperature of the start of the thermophilic mode is reached at 60 hours of the experiment, at a speed of five rpm at 72 hours, at 15 rpm at 84 hours.

The third stage of substrate fermentation is characterized by the temperature and duration of the thermophilic process. At a reactor speed of $10 \mathrm{rpm}$, the thermophilic mode lasts for 98 hours, and the temperature of the main fermentation phase is in the range from 60 to $61{ }^{\circ} \mathrm{C}$. At a frequency of five $\mathrm{rpm}$, the thermophilic mode lasts for 108 hours, and the temperature of the main fermentation phase is in the range of 55 to $58^{\circ} \mathrm{C}$. At a frequency of $15 \mathrm{rpm}$, the thermophilic mode lasts for 120 hours and the temperature of the main fermentation phase is in the range from 51 to $53{ }^{\circ} \mathrm{C}$.

The final fermentation step is characterized by a decrease in the substrate temperature below $30{ }^{\circ} \mathrm{C}$, which characterizes the end of the fermentation process. So, at a stirring frequency of $10 \mathrm{rpm}$ the process of fermentation of the substrate is 180 hours, at $5 \mathrm{rpm}-216$ hours, at $15 \mathrm{rpm}-248$ hours. The use of an optimal mixing mode reduces the fermentation time of the substrate from $16.66 \%$ to $27.42 \%$.

In our opinion, this effect of the reactor rotation on the temperature regime is explained by the fact that at a rotation speed of five rpm the substrate is insufficiently mixed and partially saturated with air, and at $15 \mathrm{rpm}$ the centrifugal force increases, which results in the substrate reducing its mobility and insufficient oxygen saturation.

During the course of the fermentation process of the substrate, periodically once a day, the acidity of the substrate was measured and its ash content was analyzed, Table 1.

Table 1

Changing the acidity and ash content of the substrate under different modes of mixing

\begin{tabular}{|c|c|c|c|c|c|c|}
\hline \multirow{3}{*}{$\begin{array}{c}\text { Fermentation } \\
\text { time, } h\end{array}$} & \multicolumn{6}{|c|}{ Mixing mode } \\
\hline & \multicolumn{2}{|c|}{$5 \mathrm{rpm}$} & \multicolumn{2}{|c|}{$10 \mathrm{rpm}$} & \multicolumn{2}{|c|}{$15 \mathrm{rpm}$} \\
\hline & $\mathrm{pH}$ & $\begin{array}{c}\text { Ash } \\
\text { content, \% }\end{array}$ & $\mathrm{pH}$ & $\begin{array}{c}\text { Ash } \\
\text { content, \% }\end{array}$ & $\mathrm{pH}$ & $\begin{array}{c}\text { Ash } \\
\text { content, \% }\end{array}$ \\
\hline 0 & 6.6 & 13.05 & 6.6 & 13.05 & 6.6 & 13.05 \\
\hline 24 & 5.9 & 13.21 & 5.9 & 13.21 & 5.8 & 13.21 \\
\hline 48 & 6.0 & 13.31 & 6.2 & 13.42 & 5.9 & 13.45 \\
\hline 72 & 6.6 & 13.52 & 6.8 & 14.27 & 6.2 & 13.56 \\
\hline 96 & 6.8 & 14.65 & 7.0 & 15.85 & 6.6 & 14.45 \\
\hline 120 & 7.0 & 15.13 & 7.1 & 16.43 & 6.8 & 14.96 \\
\hline 144 & 7.1 & 16.05 & 7.1 & 17.15 & 7.0 & 15.61 \\
\hline 168 & 7.1 & 16.58 & 7.2 & 17.61 & 7.1 & 16.05 \\
\hline 192 & 7.2 & 17.31 & 7.2 & 17.89 & 7.1 & 16.58 \\
\hline 216 & 7.2 & 17.43 & - & - & 7.2 & 17.15 \\
\hline 240 & - & - & - & - & 7.2 & 17.25 \\
\hline
\end{tabular}

Analysis of the data in Table 1 shows that in the time interval from 0 to 48 hours there is an acidic phase of fermentation, characterized by a decrease in the acidity of the substrate to 5.9 and below. Subsequently, in the process of fermentation, the acidity gradually increases and reaches a neutral value at the end of the fermentation. The change in the ash content of the substrate indicates the course of the raw material splitting in the process of substrate fermentation. The analysis of Fig. 2 and Table 1 allows concluding that the higher is the temperature of the thermophilic mode of fermentation, the more active and complete is the process of transformation of raw materials. Thus, at a reactor speed of five rpm, the ash content of the substrate during the fermentation increased by $33.56 \%$, at a frequency of $10 \mathrm{rpm}$ by $37.08 \%$ and at a frequency of $15 \mathrm{rpm}$ by $32.18 \%$. 
The results obtained allow us to conclude that by choosing the optimum mode of transport it is possible to optimize the time and completeness of fermentation of this type substrate.

Further studies should be carried out in the direction of increasing the efficiency of the drum type reactors, by finding the optimal shape of the inner blades and finding the effective composition of the substrate components.

\section{Conclusions}

Research on the process of compost mixture fermentation, consisting of $50 \%$ of pork pus and straw cut, $20 \%$ of poultry dung, $15 \%$ peat and $15 \%$ sawdust of trees of leafy breeds, in the drum type reactor allowed getting such regime parameters:

1. Effective rotation parameters of the experimental reactor were established. The obtained parameters: rotation speed $10 \mathrm{rpm}$, rotation duration $5 \mathrm{~min}$, stirring interval $55 \mathrm{~min}$. Compliance with these parameters ensures good mixing and promotes saturation of compost with air.

2. Observance of optimum parameters of mixing allows receiving the temperature range of the thermophilic mode in the range from 61 to $63^{\circ} \mathrm{C}$. The composting time of the substrate is 98 hours. Under this temperature regime of composting, there is an increase of 3.5 to $5 \%$ of the completeness of decomposition of the substrate.

\section{References}

[1] Ryabchenko O., Golub G., Turčeková N. etc. Sustainable business modeling of circular agriculture production. Case study of circular bioeconomy. Journal of Security and Sustainability, vol. 7, No. 2, 2017, pp. 301-309. DOI:10.9770/jssi.2017.7.2(10).

[2] Golub G., Kukharets S., Yarosh Y. etc. Structural models of agroecosystems and calculation of their energy autonomy. Proceedings of International conference "Engineering for Rural Development 2019”, May 22-24, 2019, Jelgava, Latvia, pp. 1344-1350. [online] [20.05.2019]. Available at: http://www.tf.llu.lv/conference/proceedings2019/Papers/N073.pdf.

[3] Lazcano C., Domínguez J. The use of vermicompost in sustainable agriculture: Impact on plant growth and soil fertility. Soil Nutrients, 2011, pp. 230-254.

[4] Chodkowska-Miszczuk J., Szymańska D. Agricultural biogas plants - A chance for diversification of agriculture in Poland. Renewable and Sustainable Energy Reviews, vol. 20, 2013, pp. 514-518. DOI:10.1016/j.rser.2012.12.013.

[5] Kozłowski K., Dach J., Lewicki A. etc. Laboratory Simulation of an Agricultural Biogas Plant Start-up. Chemical Engineering and Technology, 41(4), 2018, pp. 711-716. DOI:10.1002/ceat.201700390.

[6] Sharma K., Garg V. K. Solid-State Fermentation for Vermicomposting. Current Developments in Biotechnology and Bioengineering, 2018, pp. 373-413. DOI: 10.1016/b978-0-444-639905.00017-7.

[7] Campuzano R., Gonzalez-Martinez S. Start-up of dry semi-continuous OFMSW fermentation for methane production. Biomass and Bioenergy, vol. 136, 2020, 105544. DOI: 10.1016/j.biombioe.2020.105544.

[8] Golub G., Pavlenko S., Kukharets S. Analytical research into the motion of organic mixture components during formation of compost clamps. Eastern-European Journal of Enterprise Technologies, 3(87), 2017, pp. 30-35. DOI: 10.15587/1729-4061.2017.101097.

[9] Epstein E. Industrial composting: Environmental engineering and facilities management. Industrial Composting: Environmental Engineering and Facilities Management. 1st Edition, CRC Press, 2011, pp. 1-315.

[10]Bajko J., Fišer J., Jícha M. Temperature measurement and performance assessment of the experimental composting bioreactor, Proceedings of EPJ Web of Conferences, 2018. DOI: 10.1051/epjconf/201818002003.

[11] Singh W.R., Kalamdhad A.S., Singh J. The preferential composting of water fern and a reduction of the mobility of potential toxic elements in a rotary drum reactor. Process Safety and Environmental Protection, vol. 102, 2016, pp. 485-494. DOI: 10.1016/j.psep.2016.05.002.

[12] Alkarimiah R., Suja F. Effects of technical factors towards achieving the thermophilic temperature stage in composting process and the benefits of closed rector system compared to 
conventional method - A mini review. Applied Ecology and Environmental Research, vol. 17(4), 2019, pp. 9979-9996. DOI: 10.15666/aeer/1704_99799996.

[13] Jiang-Ming, Z. Effect of turning frequency on co-composting pig manure and fungus residue. Journal of the Air and Waste Management Association, vol. 67(3), 2017, pp. 313-321. DOI: $10.1080 / 10962247.2016 .1232666$.

[14] Golub G., Myhailovych Y., Achkevych O. etc. Optimization of angular velocity of drum mixers. Eastern-European Journal of Enterprise Technologies, vol. 7(99), 2019, pp. 64-72. DOI: $10.15587 / 1729-4061.2019 .166944 /$ 